\title{
Posterior Glenohumeral Instability in an Athlete: A Rare Sport Injury
}

\author{
Mohamed Rida El Galiou*, E. Y. Houass, M. Boufettal, R. A. Bassir, M. Kharmaz, M. O. Lamrani, M. S. Berrada
}

Department of Orthopedics and Traumatology, University Hospital Center of Rabat, Faculty of Medicine and Pharmacy of Rabat, University Mohammed V Souissi, Rabat, 10000, Morocco

DOI: $10.36347 /$ sjams.2020.v08i12.013

| Received: 26.11.2020 | Accepted: 09.12.2020 | Published: 14.12.2020

*Corresponding author: Mohamed Rida El Galiou

\section{Abstract}

Case Report

Recurrent gleno-humeral posterior dislocations represent $4 \%$ of all recurrent shoulder dislocations, their causes are diverse. The therapeutic management depends mainly on the size of Mac Laughlin's humeral notch. The authors report the case of an athlete with posterior glenohumeral instability following a first episode of posterior dislocation. Computed tomography revealed a notch occupying $35 \%$ of the humeral head. The patient underwent a bloody reduction with filling of the humeral notch by transposition of the trochin and subscapularis.

Keywords: Gleno-humeral instability, posterior dislocation, Mac Laughlin notch.

Copyright $\odot 2020$ The Author(s): This is an open-access article distributed under the terms of the Creative Commons Attribution 4.0 International License (CC BY-NC 4.0) which permits unrestricted use, distribution, and reproduction in any medium for non-commercial use provided the original author and source are credited.

\section{INTRODUCTION}

Recurrent posterior gleno-humeral dislocations represent $4 \%$ of all recurrent shoulder dislocations, their causes are diverse $[1,2]$. We report the case of a boxer who presented with a recurrent posterior dislocation of the shoulder on a humeral notch produced during the first dislocation.

\section{Clinical Observation}

A 23-year-old boxer, who previously presented with a posterior dislocation of the left shoulder following a sports trauma, this diagnosis was made on the basis of a standard X-ray. The patient had benefited from an orthopedic reduction and had his shoulder immobilized for 4 weeks, rehabilitation was performed for 2 months. Resumption of sport was authorized at 12 weeks post-trauma. From the first training session, and following an ordinary trauma; our patient represented acute pain in the left shoulder, the X-ray diagnosed a recurrent posterior dislocation of the shoulder (Fig-1). Computed tomography revealed a notch occupying $35 \%$ of the humeral head (Fig-2). A bloody reduction was performed with filling of the humeral notch by transposition of the trochin and subscapularis (Fig-3). At the last 12-month follow-up, there was no recurrence, with resumption of sport after a 12-week break.

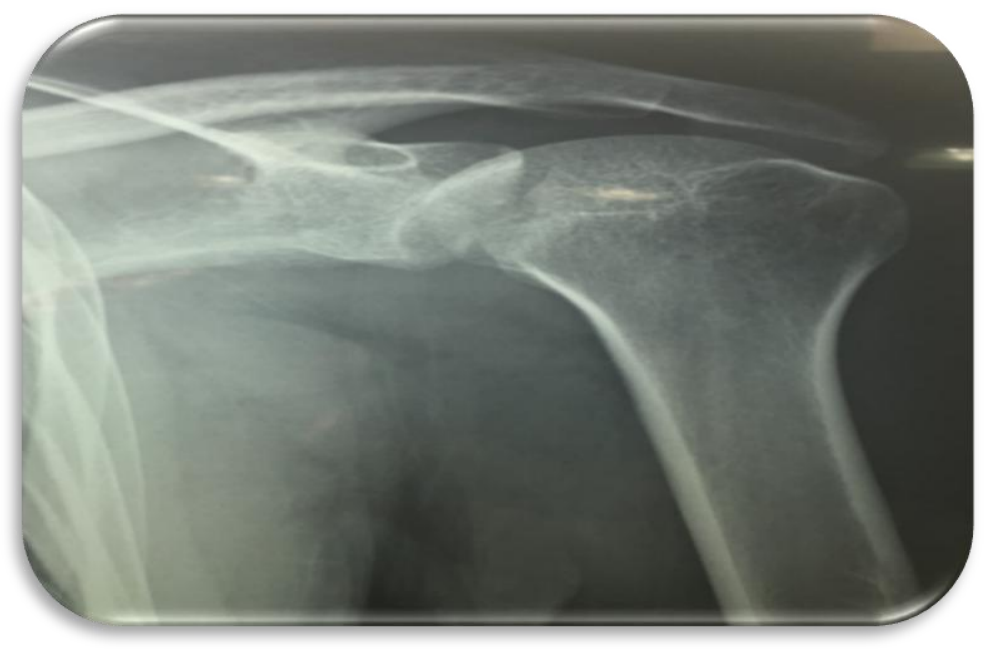

Fig-1: Radiographic appearance of posterior gleno-humeral dislocation 


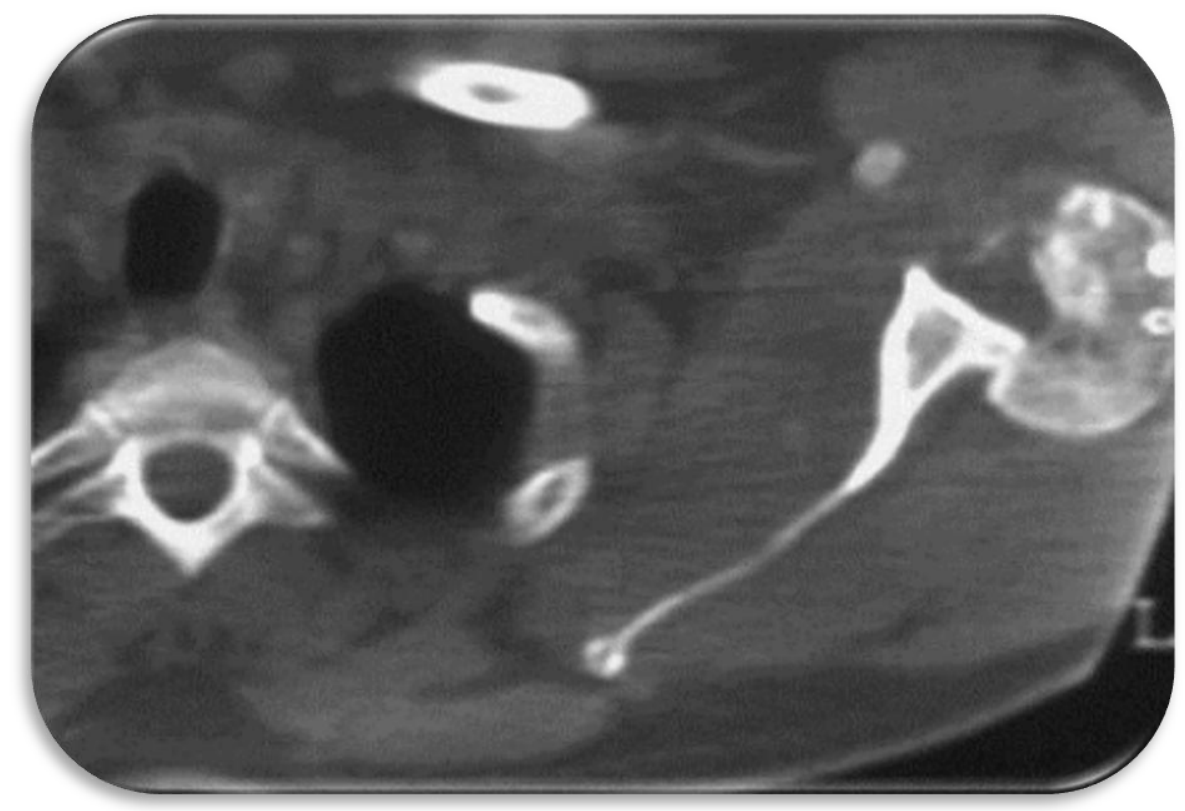

Fig-2: Tdm objectifying a Mac Laughlin notch of about 35\% of the humeral head

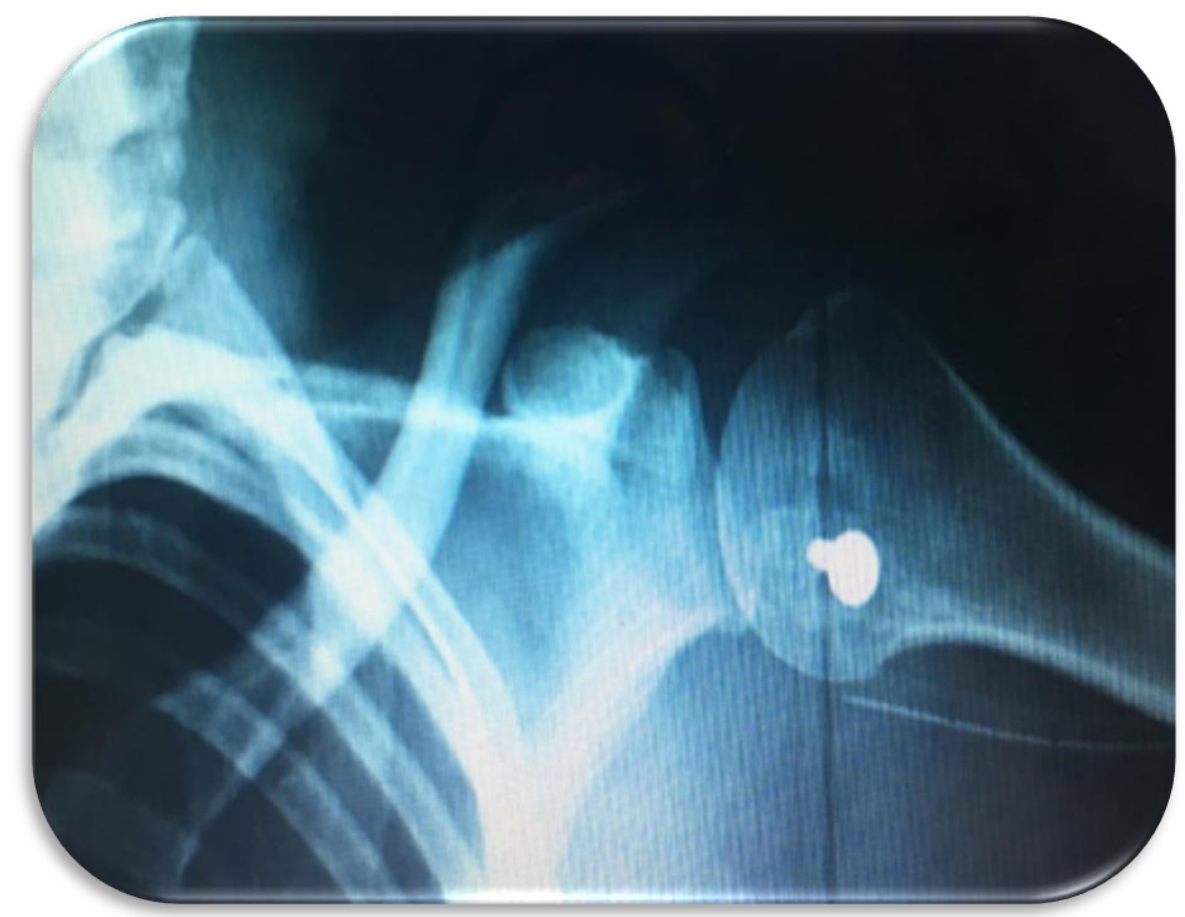

Fig-3: Radiographic control after trochin and subscapularis transposition

\section{DISCUSSION}

Posterior post-traumatic shoulder dislocation is a rare clinico-radiological situation that corresponds to approximately $2 \%$ of all shoulder dislocations [1, 3]. They are unrecognized in two thirds of cases and then progress to inveterate dislocations [4]. They are found more frequently in humans [5].

The most common complication is residual instability ranging from recurrent acute dislocation to recurrent posterior subluxation [6]. There are various causes of recurrence of a posterior dislocation of the shoulder.

The occurrence of instability depends directly on the area of the humeral bone defect in the Hill-Sachs lesion and is inversely proportional to the patient's age at the first episode of dislocation [6].

In our patient, Mac Laughlin's 35\% notch was implicated. It corresponds to an imprint created by the impaction of the posterior glenoid rim on the humeral head during displacement. Being rarely visible on the $\mathrm{x}$ - 
ray [2], performing a $\mathrm{CT}$ scan seems to be essential from the first episode in order to offer an adequate treatment.

The appreciation of the volume of this notch, called McLaughlin's, is an important element which conditions the treatment $[4,7]$; when this exceeds $25 \%$ of the humeral circumference, surgical treatment; aimed at filling the loss of bone substance; prevails [2, 3].

\section{CONCLUSION}

Knowledge of the size of Mac Laughlin's notch is a crucial factor in the management of posterior shoulder dislocation [2, 3]. For this, we strongly recommend performing a CT scan from the first episode of posterior dislocation of the shoulder.

\section{REFERENCES}

1. CICAKN. Posterior dislocation of the shoulder. J Bone Joint Surg, 2004; 86B:324-332.
2. Mc Laughlin HL: Posterior dislocation of the shoulder. J Bone Joint Surg, 1952; 34A: 584-590.

3. Robinson C, Michael B, Aderinto J. Posterior shoulder dislocations and fracture-dislocations. J Bone Joint Surg, 2005; 87A: 639-650.

4. Gerber C. Instabilités postérieures de l'épaule. In: Duparc J éd. Conférence d'enseignement de la SOFCOT $n^{\circ} 40$. Paris: Expansion Scientifique Française, 1991: 223-246.

5. Dubousset J. Luxations postérieure de l'épaule. Rev Chir Orthop. 1967; 53:65-85.

6. Robinson CM, Seah M, Akhtar MA. The epidemiology, risk of recurrence, and functional outcome after an acute traumatic posterior dislocation of the shoulder. J Bone Joint Surg Am, 2011; 93:1605-13.

7. Vandenbusche P, Augereau B. Les luxations postérieures de l'épaule. In: Cahier d'enseignement de la SOFCOT $n^{\circ}$ 49. Paris: Expansion Scientifique Française, 1994: 75-88. 